\title{
The Relationship between Psychomotor Vigilance Performance and Quality of Life in Obstructive Sleep Apnea
}

\author{
In-Soo Lee, MD'; Wayne Bardwell, PhD'; Sonia Ancoli-Israel, PhD'; Loki Natarajan, PhD²; Jose S. Loredo, MD³; Joel E. Dimsdale, MD¹
}

Departments of ${ }^{1}$ Psychiatry, ${ }^{2}$ Family \& Preventive Medicine, and ${ }^{3}$ Pulmonary Division, University of California, San Diego

Objective: Patients with obstructive sleep apnea (OSA) commonly have cognitive complaints, particularly in attention, and report decreased quality of life. We examined how vigilance and sustained attention, as assessed by the Psychomotor Vigilance Task (PVT), were related to quality of life after controlling for apnea severity and depression in subjects with OSA.

Subjects and Methods: Fifty-seven patients with newly diagnosed and untreated OSA had their sleep monitored with polysomnography. Quality of life was assessed by the Short Form36 health survey questionnaire (SF-36). Mood was assessed by the Center for Epidemiologic Studies-Depression (CES-D) Scale. After sleep monitoring and psychological assessments were performed, the 10-minute PVT was administered. The main outcome variables were PVT lapse count and average response time (RT). Simple correlations and multiple linear regression were used to examine the association between PVT performance and age, body mass index, sleep variables, apnea hypopnea index, oxygen desaturation index, and CES-D. Results and Conclusion: Both the PVT lapse count and RT were significantly associated with the SF-36 physical component summary score (PCS). In multiple linear regression, PVT RT was an independent predictor of the SF-36 PCS (full model $\left.R^{2}=0.331, p=0.003\right)$. PVT lapse was also an independent predictor of the SF-36 PCS (full model $R^{2}=0.320, p=0.004$ ). However, neither PVT RT nor lapse was a significant independent predictor of the SF-36 mental component summary score (MCS). Only CES-D was an individual predictor of the SF-36 MCS ( $\beta=-0.676, p<0.001)$. Impairments in sustained attention and vigilance may underlie the limitations in physical health-related quality of life reported by people with OSA, even after controlling for demographic variables, apnea severity, and depression.

Keywords: Obstructive sleep apnea, quality of life, SF-36, psychomotor vigilance task

Citation: Lee IS; Bardwell W; Ancoli-Israel S; Natarajan L; Loredo JS; Dimsdale JE. The relationship between psychomotor vigilance performance and quality of life in obstructive sleep apnea. J Clin Sleep Med 2011;7(3):254-260.
$\mathrm{O}$ bstructive sleep apnea (OSA) is a chronic condition characterized by repetitive upper airway obstruction during sleep, leading to apneic episodes, hypoxemia, and recurrent arousals from sleep. ${ }^{1}$ It has been estimated that $2 \%$ to $4 \%$ of middle-aged men and $1 \%$ to $2 \%$ of middle-aged women suffer from OSA, ${ }^{2}$ and the rate is even higher in older adults. ${ }^{3}$ OSA is associated with considerable morbidity and mortality, particularly from hypertension, cardiovascular disease, and insulin resistance. ${ }^{4,5}$ Furthermore, the excessive daytime sleepiness associated with OSA can result in an increased risk for motor vehicle crashes ${ }^{6}$ or serious industrial accidents. ${ }^{7}$

People with OSA commonly report having a decreased quality of life (QoL) ${ }^{8,9}$ Previous studies have reported that these patients have a significant impairments in virtually every domain of health-related QoL, with the most consistent impairments found in the domains of sleep and vitality/energy. ${ }^{10}$ Interestingly, studies have not consistently demonstrated a linear relationship between physiologic measures of OSA severity (i.e., apnea hypopnea index [AHI] or degree of nocturnal oxygen desaturation $[\mathrm{ODI}]$ ) and the degree of impairment in health-related QoL. ${ }^{11,12}$ Moreover, some studies have shown that placebo effects may play a role in some of the reported improvement of QoL that is associated with continuous positive airway pressure treatment. ${ }^{13-16}$ These findings suggest the importance of examining other potential contributing factors, such as psychological

\section{BRIEF SUMMARY \\ Current Knowledge/Study Rationale: Few studies specifically examined cognitive dysfunctions in relationship to assessments of health-related quality of life (QoL) in OSA patients. We examined the relationship between vigilance and sustained attention (as measured by Psychomotor Vigilance Task performance) and health-related QoL (as measured by SF-36) in patients with varying degrees of apnea severity. Study Impact: The findings suggest that impairments in sustained at- tention and vigilance may underlie the impairments in physical domain of heatth-related QoL reported by OSA patients, even after controlling for demographic variables, apnea severity, and depression.}

impairment and cognitive dysfunction, on impairments in QoL in people with OSA. The suggestion that cognitive dysfunction may be related to QoL is interesting because such links have been studied extensively in other populations, such as people with Alzheimer disease, in which QoL has been associated with level of cognitive impairment (e.g., memory, attention, executive function, insight) as well as other neuropsychiatric symptoms (e.g., mood, psychosis). ${ }^{17-19}$

Approximately $80 \%$ of patients with OSA have both excessive daytime sleepiness and cognitive impairment. ${ }^{20}$ Disruptions in attention and vigilance have been repeatedly noted in OSA..$^{21,22}$ Sustained attention, in particular, is one of the most commonly affected cognitive problems for OSA patients. ${ }^{23-27}$ Such cogni- 
tive disruptions are commonly assessed by several different psychomotor tests, including the Psychomotor Vigilance Task (PVT). The PVT has been demonstrated to be sensitive to sleep disruption and is regarded as an objective indicator of vigilance and sustained attention deficit in a variety of experimental conditions, such as partial sleep loss, ${ }^{28}$ chronic sleep restriction, ${ }^{29,30}$ napping, ${ }^{31}$ and sleepiness. ${ }^{32}$ In previous work, we found that PVT lapse was significantly associated with physical fatigue even after controlling for apnea severity and depression. ${ }^{33}$

Although numerous performance and imaging studies have demonstrated various cognitive impairments in patients with OSA, ${ }^{22,34-36}$ few studies have specifically examined these cognitive dysfunctions in relationship to assessments of healthrelated QoL in OSA. We examined how one aspect of cognitive dysfunction, sustained attention and vigilance (i.e., PVT average response time $[\mathrm{RT}]$ and lapse count), was related to various domains of health-related QoL in patients with varying degrees of apnea severity. We also examined if the relationship between health-related QoL and PVT performance would change after controlling for apnea severity and depression.

\section{METHODS}

\section{Participants}

Eight women and 49 men were studied as part of a larger protocol examining physiologic abnormalities in patients with and without OSA. They were recruited by advertisement and wordof-mouth referral. Participants were excluded if they reported a history of major medical illnesses (other than hypertension), had a prior diagnosis of OSA, had a current psychiatric diagnosis, were receiving psychotropic or sedative-hypnotic medication, or were receiving treatment for OSA. We recognize that hypertension may be associated with some cognitive deficits ${ }^{37}$; however, hypertension is very common in OSA, and we were concerned that, if hypertensive patients were excluded, the representativeness of the sample would be questioned and recruitment would be hampered. In addition, it should be noted that hypertension was not found to be related to the results of our cognitive testing. Patients who were receiving antihypertensive medications had their medications tapered for 3 weeks before participation. The protocol was approved by the University of California San Diego Human Subjects Committee, and all participants provided written informed consent. The design of the study enrollment is provided in Figure 1.

\section{Procedure}

Participants were admitted to the University of California San Diego General Clinical Research Center Gillin Laboratory of Sleep and Chronobiology for 2 nights. At 17:00 of the first night, they completed all questionnaires for psychological assessment. On the second night, participants had their sleep monitored from 22:00 to 6:00 the next morning, followed by PVT testing.

\section{Sleep Monitoring}

Sleep was monitored with the Grass Heritage digital polysomnograph (Model PSG36-2, Astro-Med, Inc., West Warwick, RI). Central and occipital electroencephalogram, bilateral electrooculogram, submental and tibialis anterior electromyogram,

\section{Figure 1-Recruitment profile}

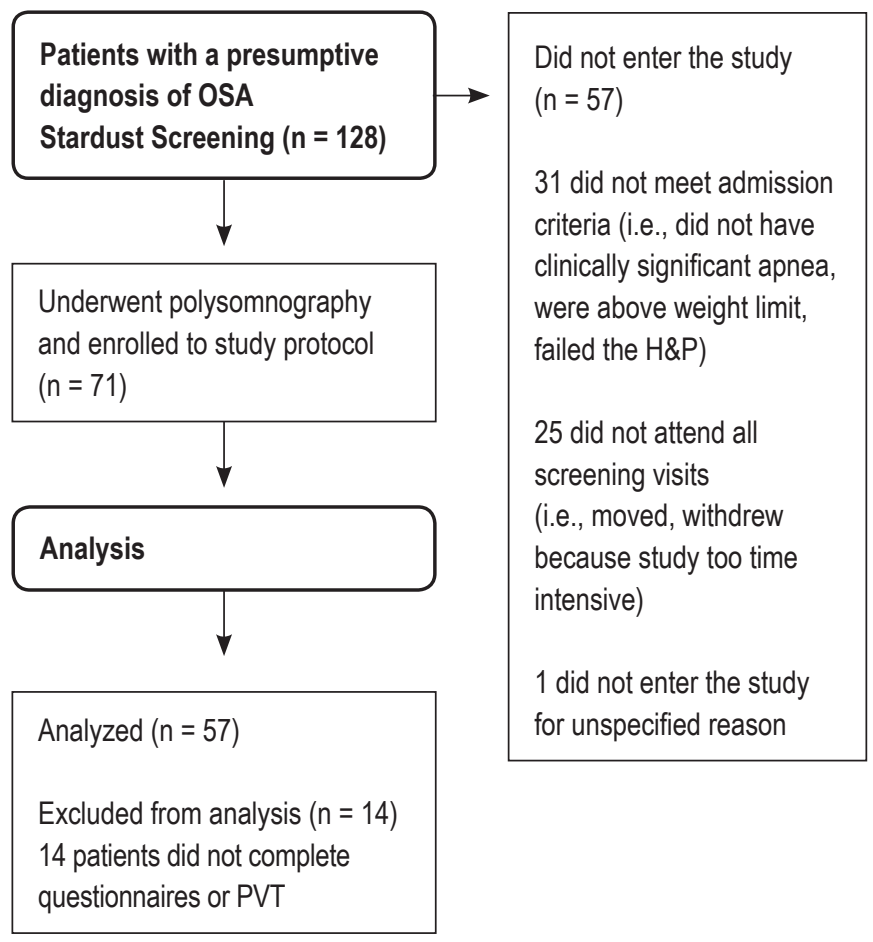

OSA, obstructive sleep apnea; H\&P, history and physical examination; PVT, Psychomotor Vigilance Task.

electrocardiogram, body position, nasal airflow using a nasal cannula-pressure transducer, and naso-oral airflow using a thermistor were assessed. Respiratory effort was measured using chest and abdominal piezoelectric belts. Pulse oximetry at the finger was used to measure transient drops in oxyhemoglobin saturation. Sleep records were manually scored according to the criteria of Rechtschaffen and Kales. ${ }^{38}$ Apneas were defined as decrements in airflow of at least $90 \%$ from baseline for at least 10 seconds. Hypopneas were defined as decrements in airflow of at least $50 \%$ but less than $90 \%$ from baseline for at least 10 seconds, regardless of the presence or absence of significant desaturations $(\geq 3 \%)$ or microarousals. The numbers of apneas and hypopneas per hour were calculated to obtain the apnea-hypopnea index (AHI). Subjects with an AHI of 10 or greater were considered to have OSA and were admitted to the study. Transient oxyhemoglobin desaturations of at least $3 \%$ from their immediate baseline lasting at least 10 seconds were scored and analyzed to obtain the ODI, the number of desaturations per hour of sleep.

\section{Depressed Mood Assessments}

The Center for Epidemiologic Studies-Depression (CES-D) Scale is a 20-item self-report scale that has been shown to be reliable and valid for assessing depressive symptoms ${ }^{39} \mathrm{CES}$-D scores of 16 or above are considered indicative of depressed mood. The CES-D primarily taps cognitive-affective aspects of depression and has been shown to be useful in groups of chronically ill patients, including those with OSA. Patients were instructed to fill out the CES-D according to how they felt in the past year. 
Table 1-Sample characteristics of 57 subjects

\begin{tabular}{|c|c|c|}
\hline Variables & Mean (SD) & Range \\
\hline \multicolumn{3}{|l|}{ Demographic Variables } \\
\hline \multicolumn{3}{|l|}{ Sex } \\
\hline Male $\quad 49(86.0 \%)$ & & \\
\hline Female $8(14.0 \%)$ & & \\
\hline \multicolumn{3}{|l|}{ Race } \\
\hline White $50(87.7 \%)$ & & \\
\hline $7(12.3 \%)$ & & \\
\hline Age (years) & $48.81(9.31)$ & $29-65$ \\
\hline $\mathrm{BMI}\left(\mathrm{kg} / \mathrm{m}^{2}\right)$ & $29.59(5.19)$ & $22.5-51.4$ \\
\hline Years of education & $15.72(2.47)$ & $10-21$ \\
\hline \multicolumn{3}{|l|}{ Sleep Variables } \\
\hline $\mathrm{AHI}\left(\right.$ events/h) ${ }^{\mathrm{a}}$ & $34.36(20.58)$ & $10.9-100.2$ \\
\hline ODI (events/h) ${ }^{\mathrm{a}}$ & $24.58(22.20)$ & $1.2-106.7$ \\
\hline \multicolumn{3}{|l|}{ Sleep Stage $(\%)^{a}$} \\
\hline Stage 1 & $12.80(8.70)$ & $2.4-48.9$ \\
\hline Stage 2 & $54.78(10.17)$ & $35.8-73.3$ \\
\hline Slow Wave Sleep & $13.53(11.13)$ & $0.0-39.2$ \\
\hline REM & $18.90(6.63)$ & $6.2-37.6$ \\
\hline \multicolumn{3}{|l|}{ PVT Variables } \\
\hline Average response time (msec) & $266.21(40.41)$ & $215.4-394.3$ \\
\hline $\begin{array}{l}\text { Count of lapses } \\
\text { (response time }>500 \mathrm{msec} \text { ) }\end{array}$ & $1.72(2.27)$ & $0-12$ \\
\hline \multicolumn{3}{|l|}{ Psychological Variables } \\
\hline CES-D ${ }^{b}$ & $11.14(8.88)$ & $0-37$ \\
\hline \multicolumn{3}{|l|}{ SF-36 } \\
\hline Physical functioning & $85.53(18.19)$ & $25-100$ \\
\hline Role limitation-physical & $68.86(39.89)$ & $0-100$ \\
\hline Bodily pain & $74.39(23.91)$ & $22-100$ \\
\hline General health perception & $71.35(17.27)$ & $20-100$ \\
\hline Energy/vitality & $54.47(19.86)$ & $15-100$ \\
\hline Social functioning & $79.25(21.01)$ & $22-100$ \\
\hline Role limitation-emotional & $76.60(35.66)$ & $0-100$ \\
\hline Mental health & $76.49(14.85)$ & $44-100$ \\
\hline $\begin{array}{l}\text { Physical component } \\
\text { summary score }\end{array}$ & $50.48(8.88)$ & $16.7-63.3$ \\
\hline $\begin{array}{l}\text { Mental component } \\
\text { summary score }\end{array}$ & $48.56(9.47)$ & $26.5-61.9$ \\
\hline
\end{tabular}

OSA, obstructive sleep apnea; BMI, body mass index; $\mathrm{AHI}$, apnea hypopnea index; ODI, oxygen desaturation index; REM, rapid eye movement sleep; PVT, Psychomotor Vigilance Task; CES-D, Center for Epidemiologic Studies Depression Scale; SF-36, Medical Outcome Survey Short Form $36 .{ }^{a} n=55 ;{ }^{b} n=56$.

\section{QoL Assessments}

The Short Form-36 health survey questionnaire (SF-36) is a generic questionnaire that has been widely used to compare the impact of different medical conditions and as an outcome measure of different therapeutic interventions. ${ }^{40}$ The questionnaire is self administered, and subjects complete 36 questions according to their experiences during the previous 4 weeks. Responses are summarized into 4 mental (mental health index, vitality, role limitations due to emotional problems, social functioning) and 4 physical (physical functioning, general health perceptions, bodily pain, role limitations due to physical health problems) subscales. These dimensions can be consolidated into separate mental and physical component summary scores (MCS and PCS). ${ }^{41}$ Scores for each scale range from 0 to100, with higher scores representing better QoL. Scores are calculated using an SF-36-specific, standardized scoring algorithm, which weighs answers from questions pertinent to each dimension. ${ }^{42}$

The internal consistency measured by Cronbach $\alpha$ for CESD was 0.682. The Cronbach $\alpha$ for SF-36 PCS and MCS were 0.589 and 0.680 , respectively.

\section{PVT Performance}

Vigilance was assessed with the PVT, ${ }^{43}$ a 10 -minute computerized visual RT task that evaluates sustained attention. Participants were instructed to respond to the appearance of a visual stimulus by pushing a response button as quickly as possible. The stimulus was a red light-emitting diode displaying time in milliseconds in a window of the portable PVT-192 device (Ambulatory Monitoring, Inc., Ardsley, NY). During each 10-minute session, visual stimuli appeared at variable intervals of 2 to 10 second. From each 10-minute PVT trial, RTs were collected and 2 performance variables - average RT and number of lapses (i.e., failure to respond or RT $>500 \mathrm{msec}$ ) — were extracted using a software program. ${ }^{43}$

\section{Statistical Analysis}

At the first stage, Pearson correlation analysis was performed to examine how PVT performance was associated with the SF36 PCS and MCS. We then examined specific SF-36 summary scores that had significant univariate correlations (i.e., $p$ value $<$ $0.05)$ with PVT performance. This analysis examined whether these QoL indices had significant associations with PVT performance variables (i.e., PVT RTs and PVT lapses) in multiple linear regression analyses that controlled for demographic, sleep, and psychological variables. To this end, SF-36 PCS and MCS were used as dependent variables; demographic variables, sleep parameters (i.e. AHI, ODI), CES-D, and PVT performance were used as independent variables.

Data were analyzed using SPSS 17.0 software (Chicago, IL). Statistical significance was set at $\mathrm{p}<0.05$.

\section{RESULTS}

Sample characteristics with means and standard deviations are presented in Table 1. As expected, the majority of subjects with OSA were male, and, on average, subjects had severe OSA and were overweight. Participants' mean age was $48.8 \pm 9.3$ years, and mean BMI was $29.6 \pm 5.2 \mathrm{~kg} / \mathrm{m}^{2}$. All participants were well educated (mean years of education $15.7 \pm 2.5$ years), and the AHI ranged from 10.9 to 100.2 (mean $34.36 \pm 20.58$ ). Mean depression scores were below the CES-D cutoff of 16 (mean $11.14 \pm 8.88$ ).

In the Pearson correlation analysis, both PVT average RT and count of lapses were significantly associated with the SF-36 PCS $(r=-0.427, p=0.001$ and $r=-0.367, p=0.005$, respectively). PVT average RT showed a significant correlation with SF-36 MCS $(r=-0.268, p=0.044)$, but PVT count of lapses did $\operatorname{not}(\mathrm{r}=-0.241, \mathrm{p}=0.071)$. 
Table 2-PVT response time as a multiple regression predictor of SF-36 physical component summary score

\begin{tabular}{|c|c|c|c|c|c|}
\hline & $\mathbf{R}^{2}$ & Adjusted $\mathrm{R}^{2}$ & Variables & $\beta$ & $\mathrm{p}$ value \\
\hline \multirow[t]{2}{*}{ Step $1^{a}$} & 0.190 & 0.159 & Age & -0.201 & 0.121 \\
\hline & & & BMI & -0.418 & 0.002 \\
\hline \multirow[t]{4}{*}{ Step $2^{b}$} & 0.252 & 0.191 & Age & -0.179 & 0.167 \\
\hline & & & BMI & -0.492 & 0.010 \\
\hline & & & $\mathrm{AHI}$ & -0.563 & 0.068 \\
\hline & & & ODI & 0.629 & 0.055 \\
\hline \multirow[t]{5}{*}{ Step $3^{c}$} & 0.258 & 0.181 & Age & -0.187 & 0.155 \\
\hline & & & BMI & -0.483 & 0.012 \\
\hline & & & $\mathrm{AHI}$ & -0.537 & 0.086 \\
\hline & & & ODI & 0.625 & 0.058 \\
\hline & & & CES-D & -0.085 & 0.526 \\
\hline \multirow[t]{6}{*}{ Step $4^{d}$} & 0.331 & 0.245 & Age & -0.158 & 0.210 \\
\hline & & & BMI & -0.440 & 0.017 \\
\hline & & & $\mathrm{AHI}$ & -0.356 & 0.249 \\
\hline & & & ODI & 0.437 & 0.180 \\
\hline & & & CES-D & -0.013 & 0.921 \\
\hline & & & $\begin{array}{l}\text { PVT response } \\
\text { time }\end{array}$ & -0.295 & 0.029 \\
\hline
\end{tabular}

PVT, Psychomotor Vigilance Task; BMI, body mass index; AHI, apnea hypopnea index; ODI, oxygen desaturation index; CES-D, Center for Epidemiologic Studies Depression Scale; SF-36, Medical Outcome Survey Short Form 36.

${ }^{a} F_{251}=5.995, p=0.005, R^{2}$ change $0.190, F$ change $p=0.005$.

${ }^{\mathrm{b}} \mathrm{F}_{4,49}^{2,51}=4.130, p=0.006, \mathrm{R}^{2}$ change $0.062, \mathrm{~F}$ change $p=0.143$.

${ }^{c} F_{5,48}^{4,49}=3.345, p=0.011, R^{2}$ change 0.006 , $F$ change $p=0.526$.

${ }^{d} F_{6,47}^{5,48}=3.873, p=0.003, R^{2}$ change $0.072, F$ change $p=0.029$.

\section{SF-36 PCS}

Table 2 presents the results of the multiple regression analysis for SF-36 PCS with various variables of interest (i.e., age, BMI, AHI, ODI, and CES-D) and PVT average RT. The full model accounted for $33.1 \%$ of the variance in the SF-36 PCS $(F=3.873, p=0.003)$. In step 1 , age and BMI account for a significant amount of variance $\left(\mathrm{R}^{2}=0.190, \mathrm{p}=0.005\right)$, and BMI was a significant individual predictor $(\mathrm{p}=0.002)$. The model at step 2, which included AHI and ODI in addition to the variables from step 1, was also significant overall $(\mathrm{p}=0.006)$, and BMI was a significant individual predictor again $(p=0.010)$. In step 3 , after the addition of CES-D to the model in step 2, the model was again significant $(\mathrm{p}=0.011)$, and BMI was still a significant individual predictor $(p=0.012)$. In step 4, after the addition of PVT average RT to the model in step3, the model was significant $(p=0.003)$ and accounted for an additional $7.2 \%$ of the variance in the SF-36 PCS. In this full model, only BMI and PVT average RT were significant individual predictors ( $\mathrm{p}=0.017$ and $\mathrm{p}=0.029$, respectively). Age, AHI, ODI, and CES-D were not significant individual predictors of the SF-36 PCS at any step of the analysis.

Table 3 presents the results of the multiple regression analysis for the SF-36 PCS with the same variables of interest in terms
Table 3-PVT lapse as a multiple regression predictor of SF-36 physical component summary score

\begin{tabular}{|c|c|c|c|c|c|}
\hline & $\mathbf{R}^{2}$ & Adjusted $\mathbf{R}^{2}$ & Variables & $\beta$ & $p$ value \\
\hline \multirow[t]{2}{*}{ Step $1^{\mathrm{a}}$} & 0.190 & 0.159 & Age & -0.201 & 0.121 \\
\hline & & & BMI & -0.418 & 0.002 \\
\hline \multirow[t]{4}{*}{ Step $2^{b}$} & 0.252 & 0.191 & Age & -0.179 & 0.167 \\
\hline & & & BMl & -0.492 & 0.010 \\
\hline & & & $\mathrm{AHI}$ & -0.563 & 0.068 \\
\hline & & & ODI & 0.629 & 0.055 \\
\hline \multirow[t]{5}{*}{ Step $3^{c}$} & 0.258 & 0.181 & Age & -0.187 & 0.155 \\
\hline & & & BMI & -0.483 & 0.012 \\
\hline & & & $\mathrm{AHI}$ & -0.537 & 0.086 \\
\hline & & & ODI & 0.625 & 0.058 \\
\hline & & & CES-D & -0.085 & 0.526 \\
\hline \multirow[t]{6}{*}{ Step $4^{d}$} & 0.320 & 0.233 & Age & -0.164 & 0.198 \\
\hline & & & BMI & -0.406 & 0.031 \\
\hline & & & $\mathrm{AHI}$ & -0.489 & 0.106 \\
\hline & & & ODI & 0.493 & 0.128 \\
\hline & & & CES-D & -0.010 & 0.940 \\
\hline & & & $\begin{array}{c}\text { PVT } \\
\text { Lapses }\end{array}$ & -0.266 & 0.045 \\
\hline
\end{tabular}

PVT refers to Psychomotor Vigilance Task; BMI, body mass index; AHI, apnea hypopnea index; ODI, oxygen desaturation index; CES-D, Center for Epidemiologic Studies Depression Scale; SF-36, Medical Outcome Survey Short Form 36.

${ }^{\mathrm{a}} \mathrm{F}_{251}=5.995, p=0.005 R^{2}$ change $0.190, F$ change $p=0.005$.

${ }^{\mathrm{b}} \mathrm{F}_{4,49}^{2,51}=4.130, p=0.006, R^{2}$ change $0.062, F$ change $p=0.143$.

${ }^{c} F_{5,48}^{4,4}=3.345, p=0.011, R^{2}$ change $0.006, F$ change $p=0.526$.

${ }^{d} F_{6,47}^{5,48}=3.686, p=0.004, R^{2}$ change $0.062,, F$ change $p=0.045$.

of PVT count of lapses. The full model accounted for $32.0 \%$ of the variance in the SF-36 PCS $(F=3.686, p=0.004)$. Through steps 1 to 3 , the models were significant overall $(p<0.05)$, and BMI was a significant individual predictor for SF-36 PCS at every step. In step 4, after the addition of PVT count of lapses to the model in step 3 (which included age, BMI, AHI, ODI, and CES-D), the model was significant $(p=0.004)$ and accounted for an additional $6.2 \%$ of the variance in the SF-36 PCS. In this full model, PVT count of lapses and BMI were significant individual predictors $(p<0.05)$. However, age, AHI, ODI, and CES$\mathrm{D}$ were not significant individual predictors of the SF-36 PCS.

\section{SF-36 MCS}

Table 4 presents the results of the linear regression analysis for the SF-36 MCS. The full model accounted for $50.1 \%$ of the variance in the SF-36 MCS $(F=7.852, p<0.001)$. The model in step 1, which included age and BMI, was not significant overall $(p>0.05)$. The model in step 2, which included AHI and ODI in addition to the variables from step 1, was not significant $(p>0.05)$. In step 3 , after the addition of CES-D to the model in step 2 , the model was significant $(p<0.05)$, accounting for an additional $44.4 \%$ of the variance of the SF-36 MCS. In step 4, after the addition of PVT RT to the model in 


\begin{tabular}{|c|c|c|c|c|c|}
\hline & $\mathbf{R}^{2}$ & Adjusted $\mathrm{R}^{2}$ & Variables & $\beta$ & $p$ value \\
\hline \multirow[t]{2}{*}{ Step $1^{a}$} & 0.029 & -0.009 & Age & 0.159 & 0.259 \\
\hline & & & BMI & -0.039 & 0.783 \\
\hline \multirow[t]{4}{*}{ Step $2^{b}$} & 0.040 & -0.038 & Age & 0.183 & 0.213 \\
\hline & & & BMI & 0.046 & 0.825 \\
\hline & & & $\mathrm{AHI}$ & -0.197 & 0.568 \\
\hline & & & ODI & 0.070 & 0.848 \\
\hline \multirow[t]{5}{*}{ Step $3^{c}$} & 0.484 & 0.430 & Age & 0.120 & 0.271 \\
\hline & & & BMI & 0.123 & 0.429 \\
\hline & & & $\mathrm{AHI}$ & 0.018 & 0.943 \\
\hline & & & ODI & 0.034 & 0.901 \\
\hline & & & CES-D & -0.711 & $<0.001$ \\
\hline \multirow[t]{6}{*}{ Step $4^{d}$} & 0.501 & 0.437 & Age & 0.134 & 0.221 \\
\hline & & & BMI & 0.144 & 0.357 \\
\hline & & & $\mathrm{AHI}$ & 0.105 & 0.691 \\
\hline & & & ODI & -0.057 & 0.839 \\
\hline & & & CES-D & -0.676 & 0.000 \\
\hline & & & $\begin{array}{l}\text { PVT response } \\
\text { time }\end{array}$ & -0.141 & 0.217 \\
\hline
\end{tabular}

PVT refers to Psychomotor Vigilance Task; BMI, body mass index; AHI, apnea hypopnea index; ODI, oxygen desaturation index; CES-D, Center for Epidemiologic Studies Depression Scale; SF-36, Medical Outcome Survey Short Form 36.

${ }^{\mathrm{a}} \mathrm{F}_{251}=0.753, p=0.476 \mathrm{R}^{2}$ change $0.029, \mathrm{~F}$ change $\mathrm{p}=0.476$.

${ }^{\mathrm{b}} \mathrm{F}_{4,49}^{2,51}=0.511, p=0.728, R^{2}$ change $0.011, F$ change $p=0.749$.

${ }^{c} F_{5,48}^{4,49}=9.003, p<0.001, R^{2}$ change $0.444, F$ change $p<0.001$.

${ }^{d} F_{6,47}^{5,48}=7.852, p<0.001, R^{2}$ change $0.017, F$ change $p=0.217$.

step3, the model was significant $(\mathrm{p}<0.05)$ and accounted for an additional $1.7 \%$ of the variance in the SF-36 MCS. Only CES-D was a significant individual predictor of the SF-36 MCS through steps 3 and 4.

\section{DISCUSSION}

This study examined the relationship between vigilance and attention, as measured by PVT performance (i.e., average RT and lapse) and health-related QoL, as measured by PCS and MCS score of the SF-36. Interestingly, vigilance or attention problems, as measured by the PVT, contribute a great deal of information concerning physical measures of health-related QoL in patients with OSA. In multiple regression analyses, these PVT measures were associated with physical domains of health-related QoL, even after controlling for important factors such as demographic measures (i.e., age and BMI), apnea severity (i.e., AHI and ODI), and depression. These results suggest that impairments in sustained attention and vigilance have a significant independent impact on decreased QoL in physical domains of patients with OSA.

Decrements in PVT performance have been shown to be associated with older age, ${ }^{44}$ higher $\mathrm{BMI},{ }^{45}$ female sex,${ }^{46}$ more sleep loss (total sleep deprivation, chronic partial sleep restriction, and sleep fragmentation), ${ }^{47,48}$ and higher AHI. ${ }^{45}$ It is difficult to sort through the implications of the independent effect of PVT performance on health-related QoL even after controlling for apnea severity. It could be, for instance, that some other measures of sleep physiology, such as arousals and decreased percentage of slow wave sleep, may provide a mechanism whereby PVT diminishes health-related QoL. ${ }^{49}$ Particularly, frequency and degree of snoring in relationship to arousal might be a variable to consider in the future study. However, given our sample size, it seems inappropriate to examine diverse polysomnography-derived variables. Thus, we focused only on the polysomnographic variables of AHI and ODI, which are so key to characterizing apnea severity. Similarly, there may be other variables associated with OSA, such as inflammation, that may explain the contributions of PVT to health-related QoL. ${ }^{50}$

One striking aspect of our findings is that apnea severity, per se, was not related to QoL. That is, once OSA was diagnosed, the QoL in our sample was not necessarily worse in those with mild versus severe OSA. This finding would appear to replicate those of Fornas and colleagues and D'Ambrosio and colleagues, who also found that the decrements in QoL associated with apnea do not represent a continuous distribution across the range of apnea severity. ${ }^{11,12}$

Depression is commonly reported and a major component of impaired QoL in patients with OSA. Previous reports concerning the relationship between depression and health-related QoL instrument assessment in OSA (i.e., the SF-36) showed that several SF-36 subscales in both mental and physical domains were correlated with depression. ${ }^{51,52}$ Interestingly, when we used the SF-36 summary scores consolidating mental and physical domains, depression showed significant impact only on the mental domain of QoL but not on the physical domain of QoL.

The study has number of limitations. Our findings are hampered by a relatively small sample size (i.e., 57 subjects) and a relatively limited age group (range, 29-65 years). Although our patients had substantial levels of apnea (range of 10.9-100.2), we studied a relatively "healthy" group of patients with OSA who were free from other medical comorbidities such as diabetes mellitus, and symptomatic coronary disease. The relationship between PVT performance and QoL may be different in a broader sample of patients with OSA. It would also be of interest to examine the relationship between PVT performance and QoL in other patient groups or in control subjects. Because of extensive sex differences in terms of mood, future larger-scale studies might well include a prominent focus on sex in examining relationships among QoL, mood, and sustained attention and vigilance, as measured by the PVT. Our study design is cross-sectional in patients whose apnea is untreated; a natural next step is to examine if these PVT deficits improve with treatment and if such improvements translate into improvements in health-related QoL.

Clinicians know that patients with OSA commonly have impaired QoL. Our observations suggest that the neurocognitive deficits (vigilance and sustained attention, as judged by PVT) may be particularly determinative of impairments in the physical domain of QoL. It would appear that those patients 
with OSA who have worse cognitive performance are more vulnerable to impairments in the physical domain of QoL. The mechanism of this link remains to be determined. In terms of emotional QoL, we found, as many other researchers have before, that those patients with OSA who have depressive symptoms have particularly impaired emotional QoL scores. This suggests that clinical interventions for mood symptoms are particularly warranted for such patients to improve their emotional QoL.

In conclusion, the findings suggest that impairments in sustained attention and vigilance may underlie the impairments in physical domain of health-related QoL reported by patients with OSA, even after controlling for demographic variables, apnea severity, and depression.

\section{REFERENCES}

1. Gibson GJ. Obstructive sleep apnoea syndrome: underestimated and undertreated. Br Med Bull 2004;72:49-65.

2. Young T, Peppard PE, Gottlieb DJ. Epidemiology of obstructive sleep apnea: a population health perspective. Am J Respir Crit Care Med 2002;165:1217-39.

3. Ancoli-Israel S, Kripke DF, Klauber MR, Mason WJ, Fell R, Kaplan O. Sleepdisordered breathing in community-dwelling elderly. Sleep 1991;14:486-95.

4. Pack Al. Advances in sleep-disordered breathing. Am J Respir Crit Care Med 2006;173:7-15.

5. Ancoli-lsrael S, DuHamel ER, Stepnowsky C, Engler R, Cohen-Zion M, Marler $M$. The relationship between congestive heart failure, sleep apnea, and mortality in older men. Chest 2003;124:1400-5.

6. Tregear S, Reston J, Schoelles K, Phillips B. Obstructive sleep apnea and risk of motor vehicle crash: systematic review and meta-analysis. J Clin Sleep Med 2009;5:573-81.

7. Dinges DF. An overview of sleepiness and accidents. J Sleep Res 1995;4:4-14.

8. Finn L, Young T, Palta M, Fryback DG. Sleep-disordered breathing and selfreported general health status in the Wisconsin Sleep Cohort Study. Sleep 1998;21:701-6

9. Baldwin CM, Griffith KA, Nieto FJ, O'Connor GT, Walsleben JA, Redline S. The association of sleep-disordered breathing and sleep symptoms with quality of life in the Sleep Heart Health Study. Sleep 2001;24:96-105.

10. Atkeson AD, Basner RC. Sleep and Quality of Life in Sleep Apnea. Totowa, $\mathrm{NJ}$ : Human Press; 2008.

11. Fornas $\mathrm{C}$, Ballester $\mathrm{E}$, Arteta $\mathrm{E}$, et al. Measurement of general health status in obstructive sleep apnea hypopnea patients. Sleep 1995;18:876-9.

12. D'Ambrosio C, Bowman T, Mohsenin V. Quality of life in patients with obstructive sleep apnea: effect of nasal continuous positive airway pressure--a prospective study. Chest 1999;115:123-9.

13. Montserrat JM, Ferrer M, Hernandez L, et al. Effectiveness of CPAP treatment in daytime function in sleep apnea syndrome: a randomized controlled study with an optimized placebo. Am J Respir Crit Care Med 2001;164:608-13.

14. Jenkinson C, Davies RJ, Mullins R, Stradling JR. Comparison of therapeutic and subtherapeutic nasal continuous positive airway pressure for obstructive sleep apnoea: a randomised prospective parallel trial. Lancet 1999:353:2100-5.

15. Barnes M, McEvoy RD, Banks S, et al. Efficacy of positive airway pressure and oral appliance in mild to moderate obstructive sleep apnea. Am J Respir Crit Care Med 2004;170:656-64.

16. Profant J, Ancoli-lsrael S, Dimsdale JE. A randomized, controlled trial of 1 week of continuous positive airway pressure treatment on quality of life. Heart Lung 2003;32:52-8.

17. Vogel A, Stokholm J, Gade A, Andersen BB, Hejl AM, Waldemar G. Awareness of deficits in mild cognitive impairment and Alzheimer's disease: do $\mathrm{MCl}$ patients have impaired insight? Dement Geriatr Cogn Disord 2004;17:181-7.

18. Matsui T, Nakaaki S, Murata $Y$, et al. Determinants of the quality of life in Alzheimer's disease patients as assessed by the Japanese version of the Quality of Life-Alzheimer's disease scale. Dement Geriatr Cogn Disord 2006;21:182-91.

19. Banerjee S, Smith SC, Lamping DL, et al. Quality of life in dementia: more than just cognition. An analysis of associations with quality of life in dementia. J Neurol Neurosurg Psychiatry 2006;77:146-8.
20. Guilleminault C, Hoed JVD, Mitler M. Clinical overview of sleep apnea syndromes. New York, NY: Allan R Liss; 1978.

21. Sateia MJ. Neuropsychological impairment and quality of life in obstructive sleep apnea. Clin Chest Med 2003:24:249-59.

22. Beebe DW, Groesz L, Wells C, Nichols A, McGee K. The neuropsychological effects of obstructive sleep apnea: a meta-analysis of norm-referenced and case-controlled data. Sleep 2003;26:298-307.

23. Ayalon L, Ancoli-Israel S, Aka AA, McKenna BS, Drummond SP. Relationship between obstructive sleep apnea severity and brain activation during a sustained attention task. Sleep 2009;32:373-81.

24. Bedard MA, Montplaisir J, Malo J, Richer F, Rouleau I. Persistent neuropsychological deficits and vigilance impairment in sleep apnea syndrome after treatment with continuous positive airways pressure (CPAP). J Clin Exp Neuropsychol 1993;15:330-41.

25. Greenberg GD, Watson RK, Deptula D. Neuropsychological dysfunction in sleep apnea. Sleep 1987;10:254-62.

26. Naegele B, Thouvard V, Pepin JL, et al. Deficits of cognitive executive functions in patients with sleep apnea syndrome. Sleep 1995;18:43-52

27. Redline S, Tishler PV, Hans MG, Tosteson TD, Strohl KP, Spry K. Racial differences in sleep-disordered breathing in African-Americans and Caucasians. Am J Respir Crit Care Med 1997;155:186-92.

28. Dinges DF, Powell JW. Sleepiness impairs optimum response capability-it's time to move beyond the lapse hypothesis. J Sleep Res 1989:366.

29. Belenky G, Wesensten NJ, Thorne DR, et al. Patterns of performance degradation and restoration during sleep restriction and subsequent recovery: a sleep dose-response study. J Sleep Res 2003;12:1-12.

30. Van Dongen HP, Maislin G, Mullington JM, Dinges DF. The cumulative cost of additional wakefulness: dose-response effects on neurobehavioral functions and sleep physiology from chronic sleep restriction and total sleep deprivation. Sleep 2003;26:117-26.

31. Dinges DF. Adult Napping and its Effects on Ability to Function. Boston, MA: Birkhäuser; 1992.

32. Philip P, Sagaspe P, Moore N, et al. Fatigue, sleep restriction and driving performance. Accid Anal Prev 2005;37:473-8.

33. Lee IS, Bardwell WA, Ancoli-Israel S, Dimsdale JE. Number of lapses during the psychomotor vigilance task as an objective measure of fatigue. $J$ Clin Sleep Med 2010;6:163-8.

34. Aloia MS, Arnedt JT, Davis JD, Riggs RL, Byrd D. Neuropsychological sequelae of obstructive sleep apnea-hypopnea syndrome: a critical review. J Int Neuropsychol Soc 2004;10:772-85

35. Ayalon L, Ancoli-Israel S, Klemfuss Z, Shalauta MD, Drummond SP. Increased brain activation during verbal learning in obstructive sleep apnea. Neuroimage 2006:31:1817-25.

36. Thomas RJ, Rosen BR, Stern CE, Weiss JW, Kwong KK. Functional imaging of working memory in obstructive sleep-disordered breathing. J Appl Physiol 2005;98:2226-34.

37. Manolio TA, Olson J, Longstreth WT. Hypertension and cognitive function: pathophysiologic effects of hypertension on the brain. Curr Hypertens Rep 2003:5:255-61.

38. Rechtschaffen A, Kales A. A Manual of Standard Terminology: Techniques and Scoring System for Sleep Stages of Human Subjects. Los Angeles, CA: UCLA Brain Information Service/Brain Research Institute; 1968.

39. Radloff LS. The CES-D scale: a self-report depression scale for research in the general population. Appl Psychol Meas 1977:385-401.

40. Garratt AM, Ruta DA, Abdalla MI, Buckingham JK, Russell IT. The SF-36 health survey questionnaire: an outcome measure suitable for routine use within the NHS? BMJ 1993;306:1440-4.

41. Ware JE SK, Kosinski M, Gandek B. SF-36 Health Survey: Manual and Interpretation Guide. Lincoln, RI: Quality-Metric Incorporated; 2000.

42. Ware JE. SF-36 Health Survey Manual and Interpretation Guide. Boston, MA: The Health Institute; New England Medical Centre; 2002.

43. Dinges DF, Powell JW. Microcomputer analyses of performance on a portable, simple visual RT task during sustained operations. Behav Res Methods Instrum Comput 1985;17:652-5.

44. Parasuraman R, Nestor P, Greenwood P. Sustained-attention capacity in young and older adults. Psychol Aging 1989;4:339-45.

45. Kim H, Dinges DF, Young T. Sleep-disordered breathing and psychomotor vigilance in a community-based sample. Sleep 2007;30:1309-16.

46. Blatter K, Graw P, Munch M, Knoblauch V, Wirz-Justice A, Cajochen C. Gender and age differences in psychomotor vigilance performance under differential sleep pressure conditions. Behav Brain Res 2006;168:312-7. 
47. Dinges DF, Pack F, Williams K, et al. Cumulative sleepiness, mood disturbance, and psychomotor vigilance performance decrements during a week of sleep restricted to 4-5 hours per night. Sleep 1997;20:267-77.

48. Lamond $\mathrm{N}$, Dorrian J, Burgess $\mathrm{H}$, et al. Adaptation of performance during a week of simulated night work. Ergonomics 2004;47:154-65.

49. Lim J, Dinges DF. Sleep deprivation and vigilant attention. Ann N Y Acad Sci 2008;1129:305-22.

50. Haensel A, Bardwell WA, Mills PJ, et al. Relationship between inflammation and cognitive function in obstructive sleep apnea. Sleep Breath 2009;13:35-41.

51. Akashiba T, Kawahara S, Akahoshi T, et al. Relationship between quality of life and mood or depression in patients with severe obstructive sleep apnea syndrome. Chest 2002;122:861-5.

52. Kawahara S, Akashiba T, Akahoshi T, Horie T. Nasal CPAP improves the quality of life and lessens the depressive symptoms in patients with obstructive sleep apnea syndrome. Intern Med 2005;44:422-7.

\section{ACKNOWLEDGMENTS}

This study was supported by NIH grant HL 44915 .

\section{SUBMISSION \& CORRESPONDENCE INFORMATION}

Submitted for publication August, 2010

Submitted in final revised form November, 2010

Accepted for publication November, 2010

Address correspondence to: In-Soo Lee, M.D., UC San Diego, 9500 Gilman DR, La Jolla, CA 92093-0804; Tel: (619) 543-5592; Fax: (619) 543-5462; E-mail: insoolee2006@gmail.com

\section{DISCLOSURE STATEMENT}

This was not an industry supported study. Dr. Dimsdale has received research support from Sepracor. Dr. Ancoli-Israel has received research support from Sepracor and Lutebook and has consulted or been on the advisory board of Ferring Pharmaceuticals, GlaxoSmithKline, Merck, NeuroVigil, Pfizer, Philips Respironics, Sanofi-Aventis, Sepracor, and Schering-Plough. The other authors have indicated no financial conflicts of interest. 